\title{
Self Ligation in Orthodontics: A Literature Review
}

\author{
Sharath Kumar Shetty ${ }^{1}$, Mohammed Mazvin Nihal ${ }^{2 *}$, Vijayananda K. Madhur ${ }^{3}$, Mahesh Kumar $\mathrm{Y}^{4}$
}

${ }^{1}$ Professor \& HOD, Department of Orthodontics \& Dentofacial Orthopaedics, K.V.G Dental College \& Hospital, Sullia, Karnataka, India

${ }^{2}$ Post Graduate Student, Department of Orthodontics \& Dentofacial Orthopaedics, K.V.G Dental College \& Hospital, Sullia, Karnataka, India

${ }^{3}$ Reader, Department of Orthodontics \& Dentofacial Orthopaedics, K.V.G Dental College \& Hospital, Sullia, Karnataka, India

${ }^{4}$ Professor, Department of Orthodontics \& Dentofacial Orthopaedics, K.V.G Dental College \& Hospital, Sullia, Karnataka, India

\author{
DOI: $10.36347 /$ sjds.2020.v07i12.004 \\ | Received: 14.12.2020 | Accepted: 23.12.2020 | Published: 24.12.2020
}

*Corresponding author: Mohammed Mazvin Nihal

Abstract

Self- ligating brackets are ligature less bracket systems that have a mechanical device into the bracket to close off the edgewise slot. These brackets secure passive or active ligation mechanism that ensures consistent full bracket engagement. Reduced friction between archwire and bracket allows more rapid tooth movement. This results in good control of tooth position through an adequately dimensioned bracket. A review of self-ligation in general has been highlighted in this article.

Keywords: Self Ligation, brackets, archwire, Orthodontics.

Copyright $(\mathcal{C} 2020$ The Author(s): This is an open-access article distributed under the terms of the Creative Commons Attribution 4.0 International License (CC BY-NC 4.0) which permits unrestricted use, distribution, and reproduction in any medium for non-commercial use provided the original author and source are credited.

\section{INTRODUCTION}

Self-ligating (SL) brackets are not new to orthodontics; they are resurging from the early $20^{\text {th }}$ century. In the mid 1930s, the Russell attachment was an attempt to enhance clinical efficiency by reducing ligation time [1]. SL brackets can be dichotomized into those with a spring clip that can press against the archwire (active) and those with a passive system of ligation, in which the clip, ideally, does not press against the wire. The claim of reduced friction with self-ligating brackets is often cited as a primary advantage over conventional brackets [2]. This occurs because the usual steel or elastomeric ligatures are not necessary, and it is claimed that passive designs generate even less friction than active ones [3, 4]. With reduced friction and hence less force needed to produce tooth movement, ${ }^{5}$ self-ligating brackets are proposed to have the potential advantages of producing more physiologically harmonious tooth movement by not overpowering the musculature and interrupting the periodontal vascular supply [2]. Therefore, more alveolar bone generation, greater amounts of expansion, less proclination of anterior teeth, and less need for extractions are claimed to be possible. Other claimed advantages include full and secure wire ligation [6], better sliding mechanics and possible anchorage conservation [3, 4], decreased treatment time, longer treatment intervals with fewer appointments [3, 7, 8], chair time savings, less chair-side assistance and improved ergonomics [7-12], better infection control [10], less patient discomfort [3, 4], and improved oral hygiene [11-13]. However, self-ligating brackets have some disadvantages, including higher cost, possible breakage of the clip or the slide, higher profile because of the complicated mechanical design, potentially more occlusal interferences and lip discomfort, and difficulty in finishing due to incomplete expression of the archwires. The increasing use of sliding mechanics in orthodontics has led to considerable research interest in the frictional forces developed between the archwire and bracket, which may inhibit tooth movement, require larger retraction forces and lead to anchorage taxation. Much of this research has led to the development of arch wires of differing materials and properties, along with a plethora of brackets, differing in material, construction and design, appropriate to the technique with which they are to be used [14].

\section{DEFINITION}

Self-ligating brackets by definition do not require an elastic or wire ligature but have an inbuilt mechanism that can be opened and closed to secure the archwire [15].

Properties of an ideal ligation system:

Ligation should be:-

- Be secure and robust

- Ensure full bracket engagement of the archwire

- Exhibit low friction between bracket and archwire

- $\quad$ Be quick and easy to use 
- Permit easy attachment of elastic chain

- Assist good oral hygiene

- Be comfortable for the patient [16].

Advantages of Self-ligating Brackets

- A secure passive or active ligation mechanism that ensures consistent full bracket engagement.

- $\quad$ Reduced friction between the arch wire and the bracket that allows more rapid tooth movement

- Good control of tooth position through an adequately dimensioned bracket.

- Less chair side assistance.

- Faster arch wire removal and ligation [17].

\section{CLASSIFICATION}

Based on the mode in which they interact with arch wire

i. Active

ii. Passive

iii. Interactive

\section{Active}

- Active brackets use a flexible component to entrap the arch wire.

- This flexible component constrains the arch wire in the arch wire slot and has the ability to store and subsequently release energy through elastic deflection.

- This gentle action imparts a light but continuous level of force on the tooth and its supporting structures, resulting in precise and controlled movement [18].

\section{Passive}

- Passive brackets use a rigid, movable component to entrap the arch wire.

- Tooth control with passive brackets is determined solely by the fit between bracket slot and arch wire.

- As a result, tooth control frequently is compromised with undersized wires housed in what is essentially an arch wire tube [19].

i. Damon

ii. Smartclip

iii. Glide

\section{Interactive}

Single self ligating bracket system used successfully hygienic, non degrading and non binding arch wire engagement while they simultaneously maintained a mild seating force on active arch wires for complete tooth control and optimal time efficiency.

Eg:

Time

In - ovation

Bioquick

Empower

Specific requirements for a self-ligating bracket:

- $\quad$ Easy to open and close with low forces applied to the teeth during these procedures and with all archwire sizes and materials.

- Never opens inadvertently, allowing loss of tooth control.

- Has a ligating mechanism that never jams or breaks or distorts or changes in its performance through the treatment period.

- Has a positively held open clip or slide position, so that the clip or slide does not obstruct the view of the bracket slot or the actual placement of the archwire.

- Tolerant of a reasonable excess of composite material without obstructing the clip or slide mechanism.

- Not significantly affected by buildup of calculus [20].

- Permits easy attachment and removal of all the usual auxiliary components of an appliance such as elastomeric chain, under-tie ligatures, and laceback ligatures without interfering with the self-ligating clip or slide.

- Permits easy placement and removal of hooks and posts and possibly other auxiliaries on the brackets

- Has a suitably narrow mesiodistal dimension to take advantage of the secure archwire engagement and permit large interbracket spans and hence lower force levels and a longer range of action.

- Has the performance expected of all orthodontic brackets in terms of bond strength, accuracy of slot dimensions, and smoothness of contour 


\section{Evolution of Self Ligation Bracket}

\begin{tabular}{|c|c|c|c|c|}
\hline Year & Bracket & Active/passive & Available & Mechanism \\
\hline 1935 & Russel lock & Active & No & Circular thread opening \\
\hline 1972 & Ormco Edgelok & Passive & No & Rigid sliding clip \\
\hline 1980 & Forestadent Mobil-Lock & Passive & No & Rigid rotational disk \\
\hline 1980 & Strite Industries SPEED & Active & Yes & Flexible spring clip \\
\hline 1986 & "A" Company Activa & Passive & No & Rigid rotational arm \\
\hline 1996 & AdentaTime & Passive & Yes & Rigid rotational arm \\
\hline 1996 & "A" Company Damon SL & Passive & Yes & Solid indented slide \\
\hline 1998 & Ormco TwinLock & Passive & No & Solid labial slider \\
\hline 2000 & Ormco/ $/ \mathrm{A}^{\prime \prime}$ Co. Damon 2 & Passive & Yes & Solid indented slide \\
\hline 2000 & GAC In- Ovation & Active & Yes & Flexible spring clip \\
\hline 2001 & Gestenco Oyster & Passive & Yes & Unique snap-on cap \\
\hline 2002 & Forestadent Philippe lingual bracket & Passive & Yes & Flexible tie wing \\
\hline 2002 & $\mathrm{GAC}$ In- Ovation $\mathrm{R}$ & Active & Yes & Flexible spring clip \\
\hline 2002 & Adenta Evolution LT & Passive & Yes & Rotating flexible type clip \\
\hline 2004 & Ultradent OPAL & Passive & Yes & Flexible hinge \\
\hline 2004 & Ormco Damon 3 & Passive & Yes & Rigid solid slide \\
\hline 2004 & 3 M Unitek SmartClip & Passive/active & Yes & Mesial and distally placed Flexible clips \\
\hline 2005 & Ormco Damon $3 \mathrm{MX}$ & Passive & Yes & Rigid solid slide \\
\hline 2006 & Ultradent OPAL metal & Active/passive & Yes & Flexible Hinge \\
\hline 2006 & Forestadent Quick & Passive & Yes & Snap flexible spring \\
\hline 2006 & Lancer Praxis Glide & Passive & Yes & Removable multiplanar clip \\
\hline 2006 & GAC system C & Passive & Yes & Flexible clip \\
\hline 2006 & GAC inovation $\mathrm{L}$ & Passive & Yes & Flexible clip \\
\hline 2006 & GAC innovation $\mathrm{C}$ & Passive & Yes & Flexible clip \\
\hline 2007 & $3 \mathrm{~m}$ unitek clarity SL & Active/passive & Yes & Flexible clip \\
\hline 2007 & American Orthodontics vision LP & Passive & Yes & Flexible clip \\
\hline 2007 & Dentauraum discovery & Passive & Yes & Flexible lid \\
\hline 2009 & Ormco Damon 0 & Passive & Yes & Flexible sliding clip \\
\hline 2009 & Ormco Damon aesthetic & Passive & Yes & Flexible sliding clip \\
\hline 2009 & Smartclip sl3 & Active/passive & Yes & Mesial and distal flexible clips \\
\hline 2010 & Cabriolet & Active/passive & Yes & Flexible sliding clip \\
\hline 2011 & Harmony lingual & Active/passive & Yes & Flexible sliding clip \\
\hline 2012 & Sensation Ceramic & Active & Yes & Flexible sliding clip \\
\hline 2014 & BioQuick & Passive & Yes & Flexible sliding clip \\
\hline 2014 & Carriere SLX & Passive & Yes & Flexible sliding clip \\
\hline 2015 & ProGate I & Passive & Yes & Flexible sliding clip \\
\hline 2016 & Empower 2 & Active/passive & Yes & Flexible sliding clip \\
\hline 2017 & In-0vation X & Active & Yes & Flexible sliding clip \\
\hline 2017 & Lotus Plus DS & Active/passive & Yes & Flexible sliding clip \\
\hline
\end{tabular}

\section{Russell Lock Edgewise Attachment}

Presented in the mid-1930s as the Russell attachment by New york orthodontic pioneer Dr. Stolzenberg. The section had a flat head screw situated cozily a round about, threaded opening in the face of the bracket that allows for quick and Simple arch wire changes [21].

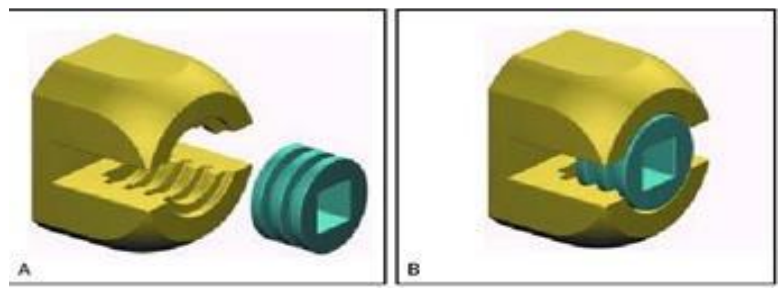

\section{Edgelock Bracket}

The first modern passive self-ligating section (Edgelok-Ormco) was presented in the early 1970's . Had a round body with a rigid labial sliding cap. An uncommon opening device was utilized to move the slide occlusally for archwire inclusion. At the point when the cap was shut over the arch wire with Finger Pressure, the section opening was changed over to a tube. The inflexibility of this external fourth divider rendered the section "passive" in its transaction with the archwire 


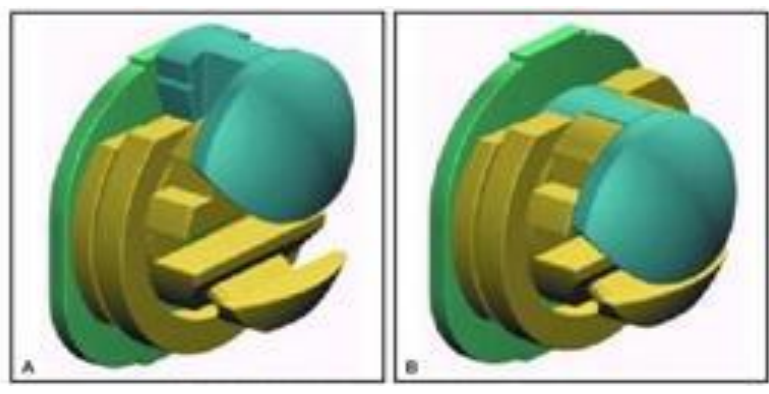

\section{Mobilock Bracket}

In 1974, Dr. Franz Sander created Mobil-lock Brackets (Forestadent, Germany). Had a rotation cam that was turned with a screw driver, thus covering part of labial surface of the slot. Wire could be tightly or loosely engaged by the degree of rotation of the cam. Well engineered by the standards of the day [22].
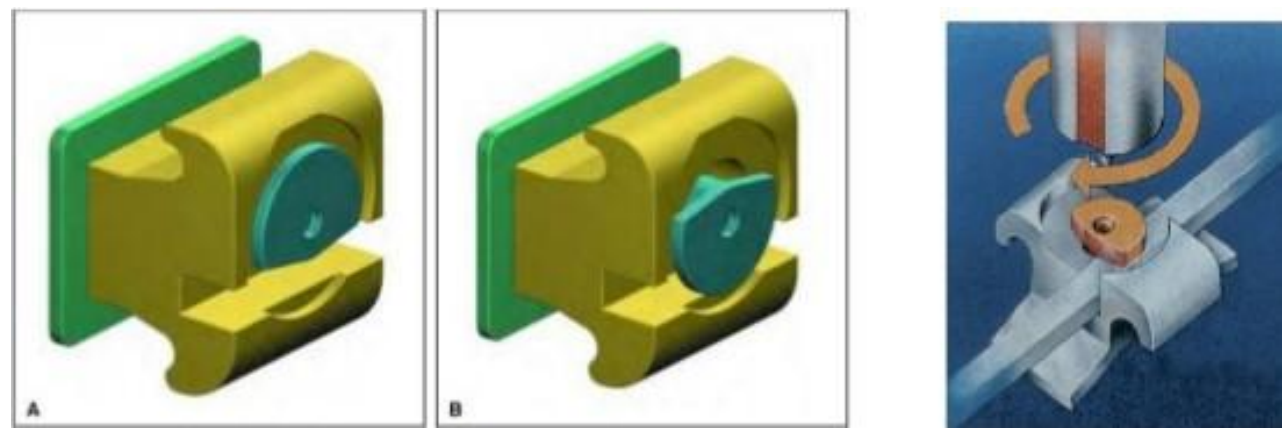

\section{Speed Bracket}

SPEED is a fully pre-adjusted miniaturized edgewise appliance that uses a super-elastic nickel titanium \&are specifically designed for each individual tooth. Each attachment consists of Five components-

1. Multi slotted bracket body.

2. An in-out adapter.

3. Permanently installed super elastic nickel titanium spring clip

4. Micro-Retentive Mesh bonding base.

5. An Integral Mushroom Hook

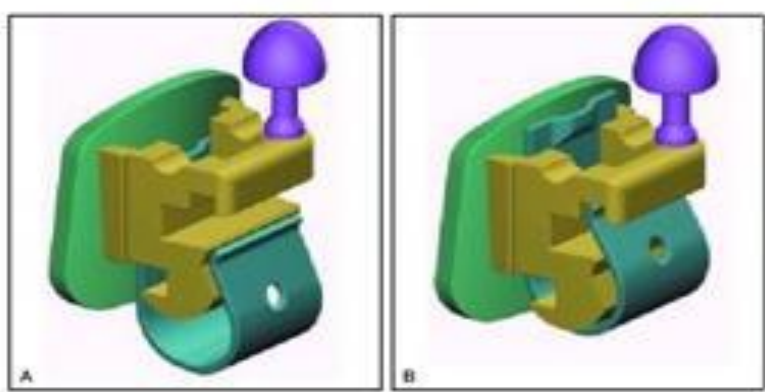

\section{Activa Bracket}

In 1986, Dr. Erwin Pletcher developed Activa bracket ("A" company). Activa bracket had an inflexible, curved arm that rotates occluso-gingivally around the cylindrical bracket body. The clips can be opened and closed with an extensive variety of usually utilized hand instruments including ligature tuckers, flat plastics, and Mitchell's trimmers. All brackets have vertical slots behind the arch wire channel [23].

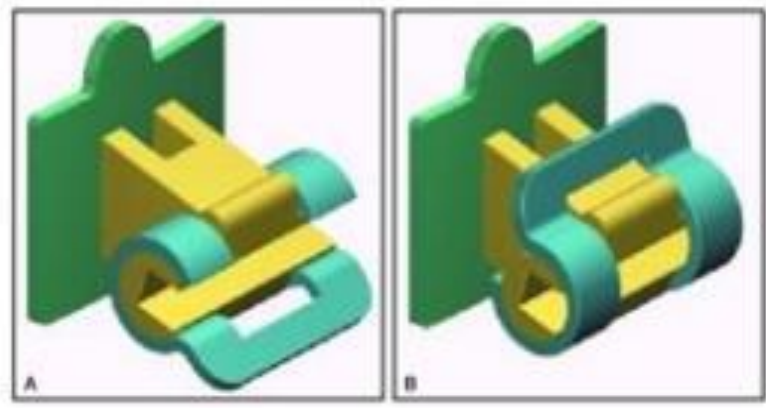

\section{Time Bracket}

In 1994 Dr. Wolfgang Heiser, developed the Time bracket which is similar in appearance to the SPEED bracket, but are significantly different in design $\&$ mode of action. First one-piece self-ligating system developed using CAD/CAM technology. Hybrid self ligating bracket. Time features a rigid, curved arm that wraps occluso-gingivally around the labial aspect of the bracket body. Can be opened either with a dental probe or with its special instrument. It is utilized to rotate the arm gingivally into the slot-vacant position or occlusally into the slot-shut position [24].

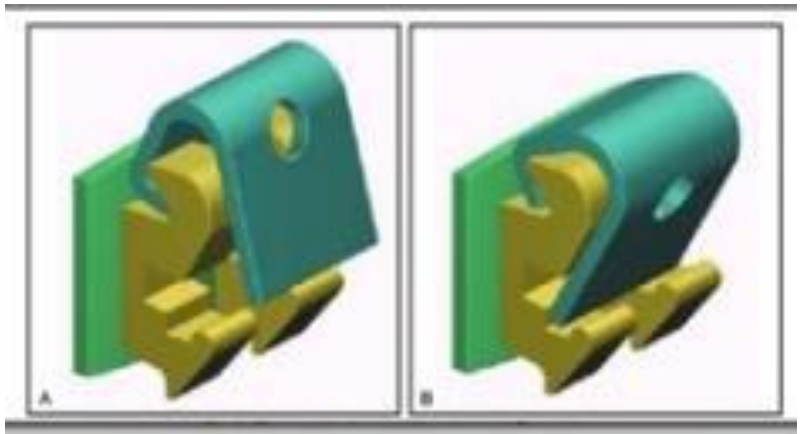




\section{Damon bracket: Damon SL}

These brackets are introduced in 1996 by Dwight Damon. It had a slide, which moved vertically on the labial Surface of an otherwise fairly conventional twin tie-wing bracket. The slide clicked into a positive open or shut position and opened in a downward direction in both jaws to give a full view of the slot. A tiny U-shaped wire spring lay under the slide and clicked into the two labial 'bulges' on the slide to provide positive open and shut positions [25].

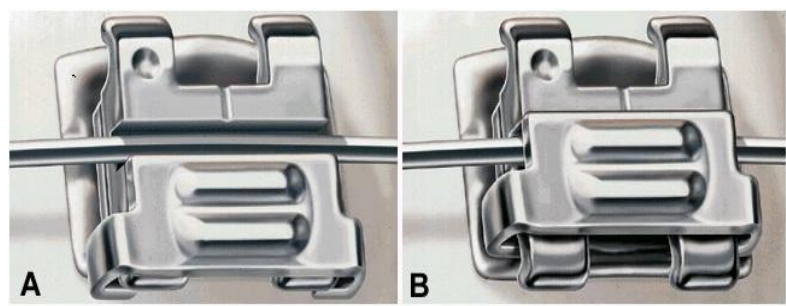

\section{Twinlock Bracket}

In 1998, Dr. Jim Wildman developed TwinLock bracket. Its flat, rectangular slide, housed between the tie wings of an edgewise twin brackets. Passive slide moved gingivally with finger pressure to entrap the arch wire in a passive configuration $\&$ it is moved occlusally into the slot-open position with a universal scaler. Additional benefits include improved hygiene and patient comfort, smooth and clean labial surface. Drawback include mobility of the slide during opening and closing obsolete its commercial achievement [26].

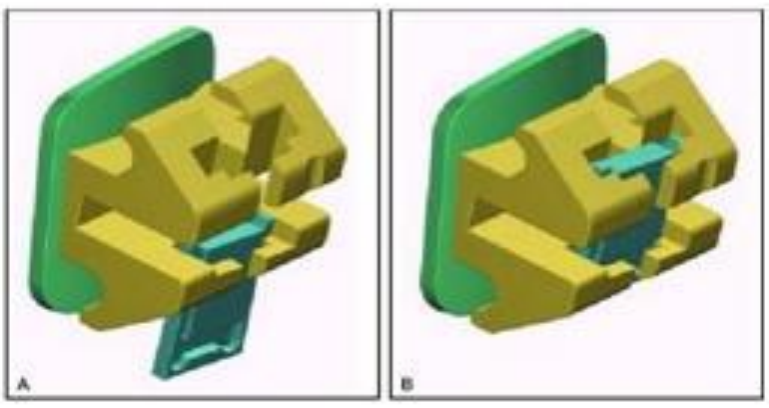

\section{Damon 2 Bracket}

The blemishes in the Damon SL brackets prompted the improvement of Damon 2 brackets 2000 which hold a similar vertical slide activity and Ushaped spring to control the opening and closing. However, put the slide inside the shelter of the tiewings. Joined with the metal injection moulding manufacture, which allows closure tolerances, these advancements have totally disposed of incidental slide opening or slide breakage. Albeit special and excellent slide-opening devices are given these brackets, they can after some training be effectively opened and shut with conventional light-wire pliers in blend with the CoolDevice archwire-seating instrument [27].

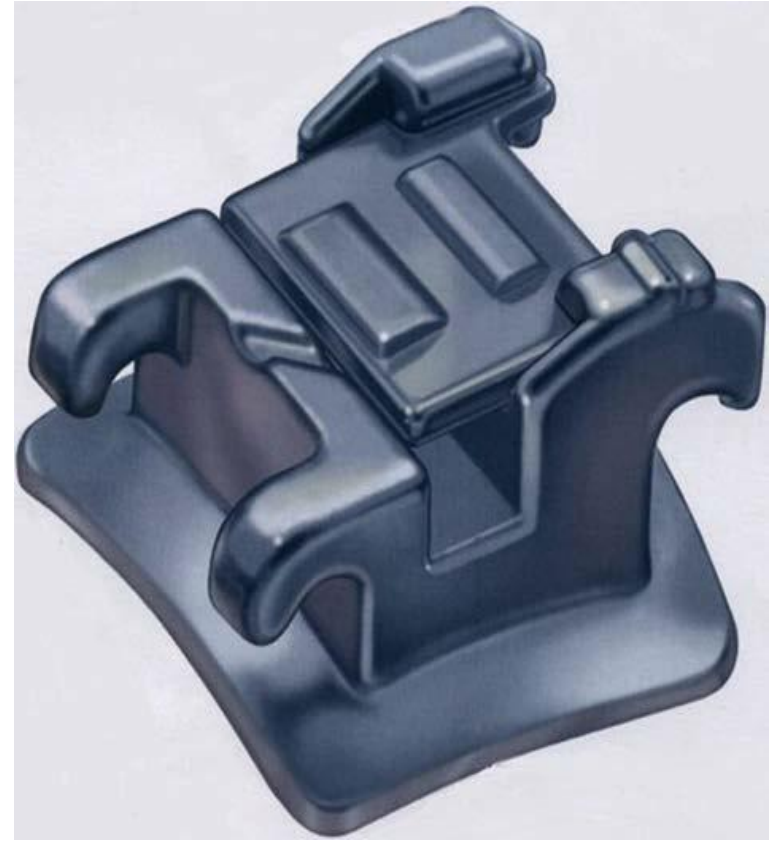

\section{GAC - Inovation Bracket}

These brackets are introduced by Micheal Calpern in 2000 [28]. These are very similar to speed brackets in concept and design, but are of-

1. Twin configuration.

2. Bracket manufactured with metal injection moulding.

3. $\mathrm{V}$-Tool (Tweezer) is used for opening the clip.

4. Active clip which is made from cobalt chromium alloy is highly resistant to fracture.

5. Slot Blocker: It prevents archwire from escaping from the bracket and enhances Torque Expression.

6. Horizontal Slot: This Slot runs through the occlusal wings which can be used for Rotation and uprighting springs or Segmental wire.

7. Super mesh Base: This houses a wide mesh over a tight mesh which enhances retention.

\section{Innovation:}

- Innovation $\mathbf{R}$-These brackets are narrow in width than in-ovation brackets. This increase benefit of their use in small tooth, lower anteriors. impacted tooth, partially erupted tooth.

- Innovation C - Esthetic innovation brackets.

- Innovation L MTM-With these lingual braces indirect bonding of anterior teeth (3-3) can be carried out. 


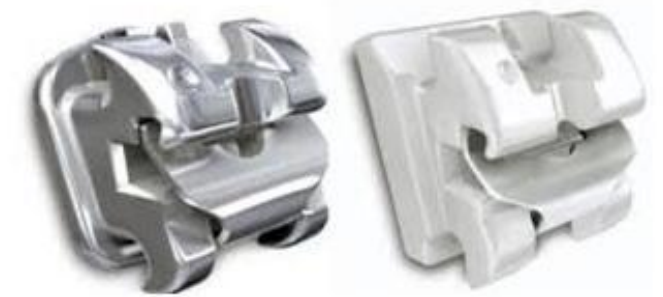

\section{Innovation L - Lingual Innovation Braces}

These brackets are like the SPEED brackets in origination and configuration, yet are of a twin arrangement . They are a decent, robust design, and no breakage of the clips has been actually tested or reported.

Some moderately minor drawbacks in bracket handling are-

- A few brackets are difficult to open. This is unpredictable but more typical in the lower arch where the gingival end of the spring clip is hard to visualize.

- These brackets are to a great degree simple to close before the archwire is in position, more probable in the lower arch

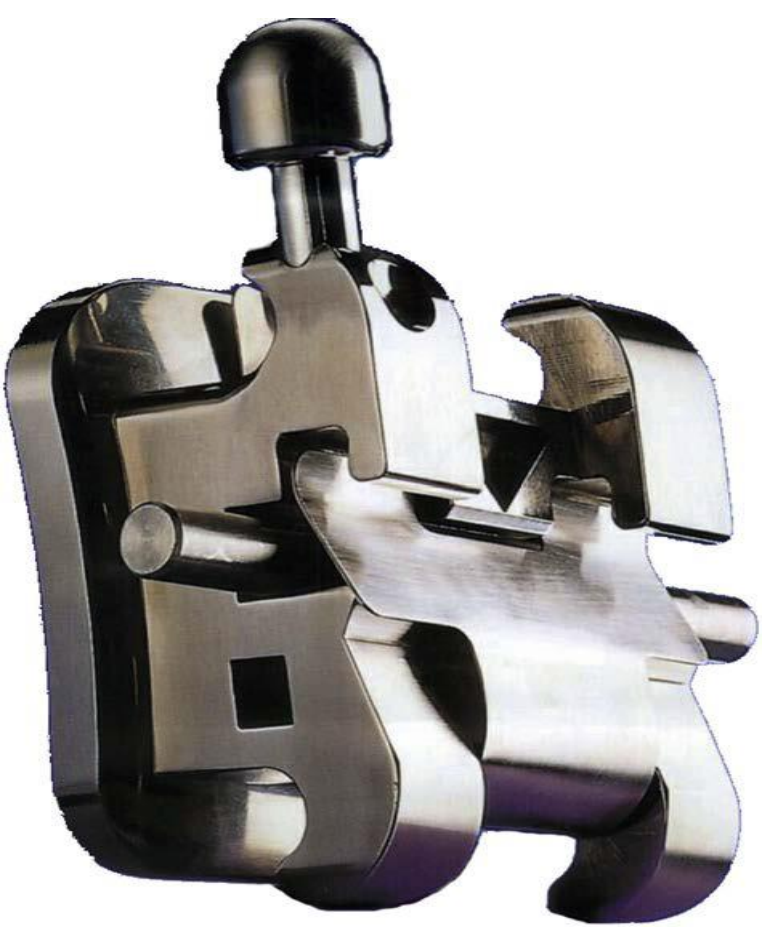

\section{Gestenco Oyster Brackets}

This was the first translucent self ligating Bracket which was introduced in 2001. The Oyster bracket is semi-translucent polycarbonate bracket and it resists discoloring as it is made from strong, fiber glass reinforced composite polymer S. Use of Super elastic and Beta arch wires are strongly recommended. The unique snap-on cap allows arch wires to be placed easily, since the cap is convertible, it can be removed if necessary and the bracket will function as a regular twin. Mushroom Hook is present for auxiliary attachment. Its drawback was high friction that is equivalent to Conventional stainless steel brackets, So not used now.

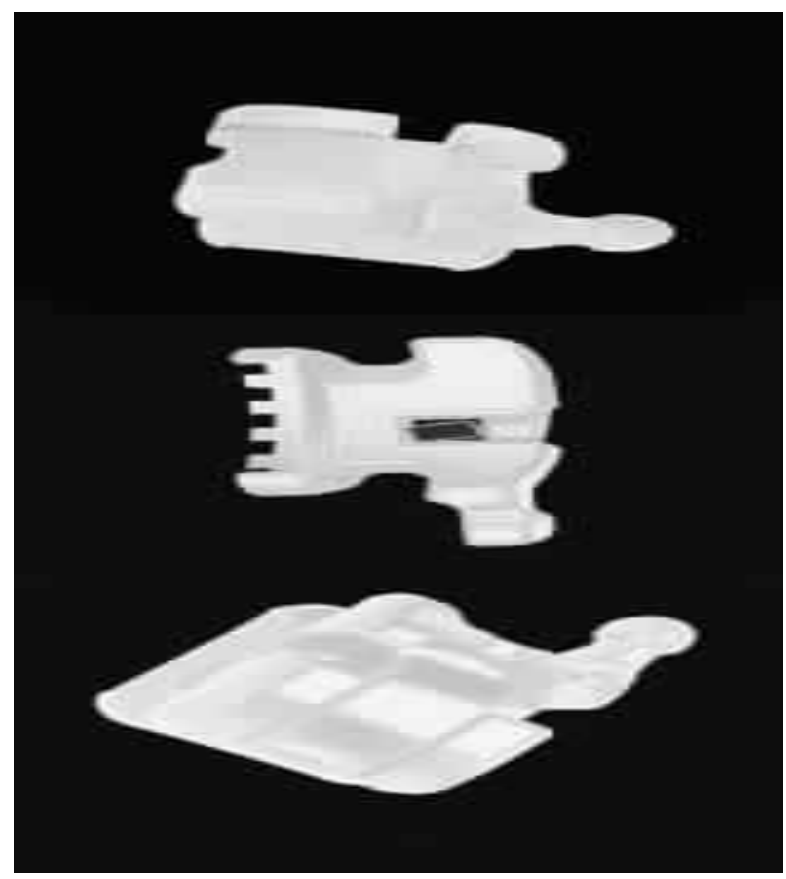

Philippe Lingual Self Ligating Bracket

Philippe passive self ligating bracket developed (forestadent) by Aldo Macchi 2002 Philippe 2D self-ligating lingual brackets providing 2dimensional control, were suggested for the correction of simple malocclusions, such as minor crowding or spacing with the lingual technique. The primary preferred standpoint of the Philippe brackets is their position of safety and their comfort to the patients. They are reasonable for basic cases that don't require 3dimensional control since they have no slot. These brackets can be bonded straight forwardly to the lingual surface of the tooth. These brackets have no slot, they incorporate little wings welded to the base of the bracket. Four kinds of Philippe brackets are accessible standard medium twin, a limited single-wing bracket for lower incisors, a large twin and a three-wing bracket. Bracket wings used to secure the archwire to slot, are opened with Haideman spatula and shut with Weingart plier [29]. 


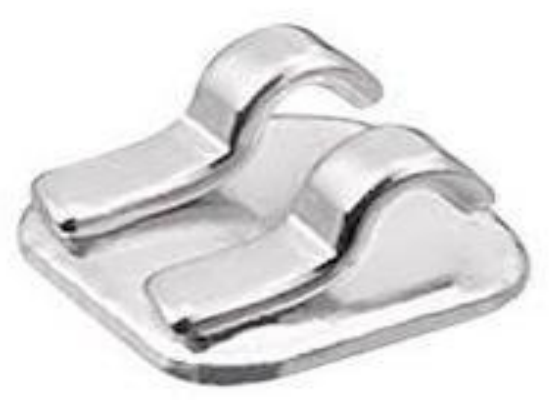

Adenta Evolution Brackets

It is developed by Dr. Hatto Loidl and C. Schendell 2001 Designed as a one piece bracket with a clip that opens at the incisal edge and allows insertion of the archwire from the occlusal direction. The clip can serve also as a bite plate, and consequently presses the archwire further into the slot when biting [30].
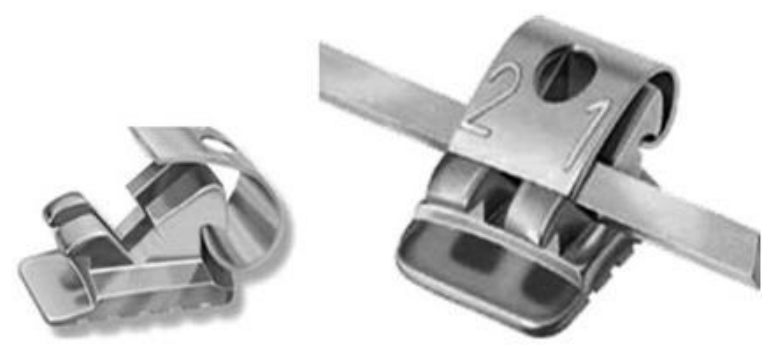

\section{Opal Brackets}

It is a completely non metallic bracket, designed and developed (ultradent) by Dr. Norbert Abels 2004 Completely nonmetallic (resin) Bracket work as a compelling slot and sufficiently flexible in pivot region to open and close. The opal configuration is somewhat brilliant in this regard however mind must be taken not to fatigue fracture the hinge portion of the bracket by the repeated full opening of the cap. The brackets like most resin, are maybe most appropriate for the short course of treatment where these issues of lifespan are less of an issue. There are no tie wings, so elastic chain is put in before shutting the cap.

\section{Smart Clip}

It is introduced and developed (3M Unitek) by Gary L. Weinberger in 2004. It consists of two nickel titanium clips i.e., mesial and distal tie wings that open and close through elastic deformation of the material when the arch wire exerts a force on the clip. The bracket contains no moving door or latch. The feature of no moving doors or latches can eliminate problems such as sticking, spontaneous opening, or plaque buildup that are associated with other types of self ligating brackets [31].

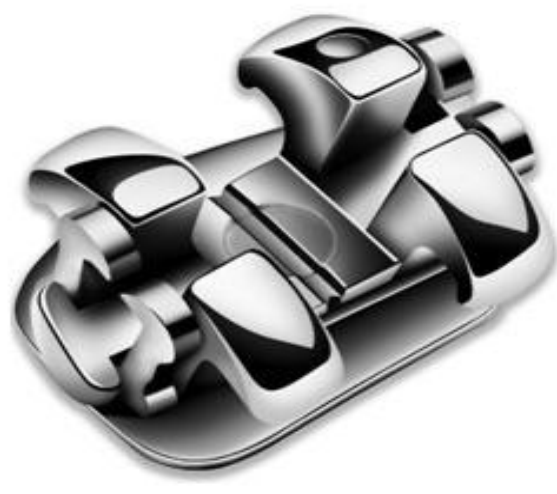

Opal Metal Bracket

It is Completely non metallic bracket. It is Designed \& developed by Dr. Norbert Abels. Entirely nonmetalic bracket function as an effective slot and flexible enough in hinge area to open and close. No tiewings so elastic chains placed prior to closing the cap. Best suited for short course of treatment.
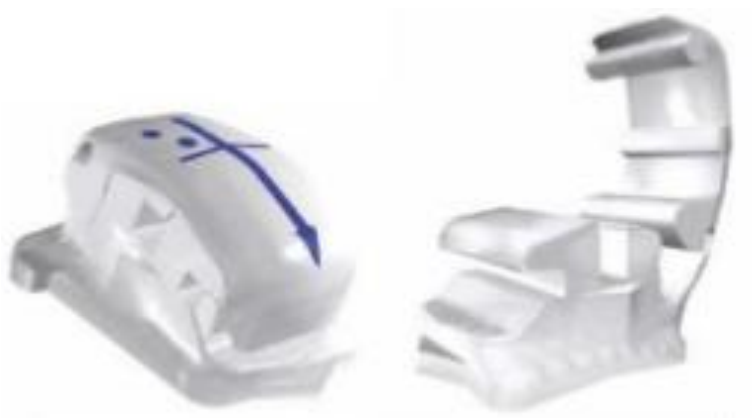

\section{Forestadent Quick}

It is developed by Dr. Bjorn Ludwig 2006 It available both active (bioquick) and passive (biopassive). Externally passive brackets differentiated from active by a vertical marks on metal ligature wing. It consist of snap flexible spring, is opened with probe from the gingival end. Optimized, anatomically positioned base prevents rocking of the bracket when it is pressed on the tooth [32].

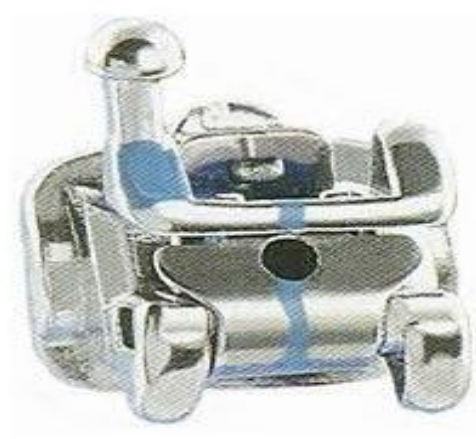

\section{Lancer Praxis Glide}

It is developed by Dr. Robert Lokar and team of Lancer Orthodontic engineers is truly an innovative 
low friction hybrid twin system, are manufactured using the latest robotic Technology. Praxis Glide is a proven torque-in-the base twin bracket, with a removable multiplanar clip. PraxisTSTM bracket is the latest mid aesthetic appliance now offered by LANCER [33].

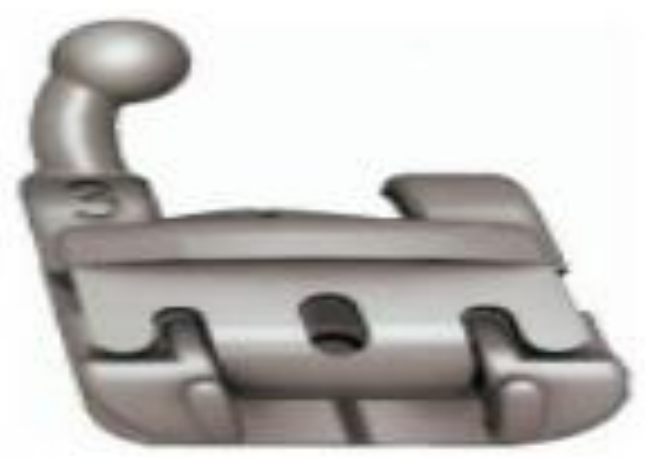

\section{Smart Clarity SL bracket (2007)}

It is ceramic version of smart clip bracket with improved clip forces.
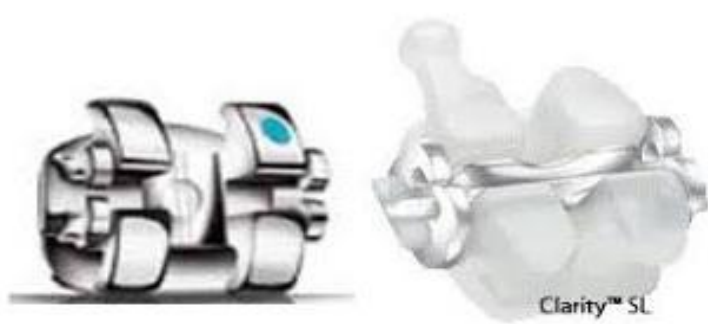

\section{Vision LP}

These brackets are fully passive, having low profile, no bio-debris binding as it has very small contact point \& located at the face of bracket so that it can be cleaned everytime the patient brushes. Along with maintaining low friction mechanics it also provides high, standard \& low torque options for customized treatment. Vision LP brackets has strong \& durable clip which was designed such that it is easy to open \& close. Opened with instrument by simple rotation \& closed by clicking gently with instrument or fingernail. It is having individual color coding \& maximum retention technology bonding base [34].

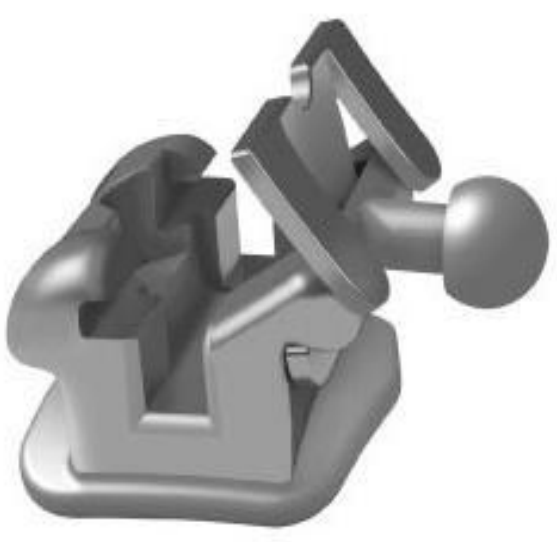

\section{Discovery Brackets}

It is developed by dentauram in 2007 using CAD CAM technology. Features are-

1. Best therapy results with minimal size for aesthetic treatment.

2. High degree of user convenience due to easy locking mechanism

3. Improved, flexible lid stop keeps the lid open for quick, smooth archwire change.

4. New opening mechanism in the direction of force guarantees numerous perfect opening and closing operations.

5. Revised bracket geometry to ensure that the lids always open straight. This prevents buckling of the lid.

6. Super smooth surfaces provide excellent intraoral comfort for the Patient.

7. FDI notation on the base ensures easy assignment to each tooth.

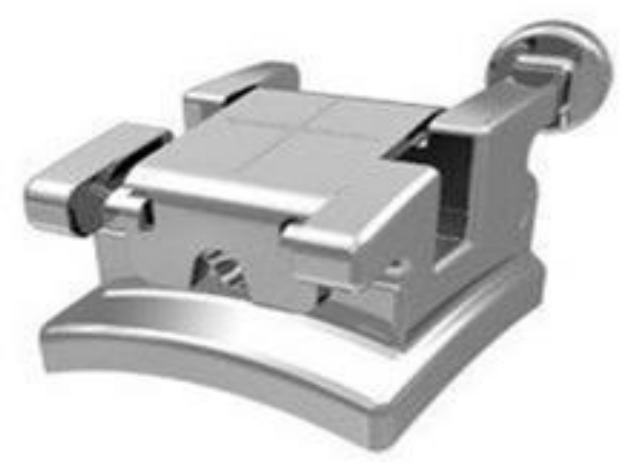

\section{Damon Q (2009)}

Sliding component is intended to be simpler, more secure and more comfortable to the patient when opened and shut and resistant to the impacts of calculus accumulation. These brackets likewise smaller in all measurements than their predecessors and space has been found for horizontal and vertical slot. Spintec cool - opening tool 

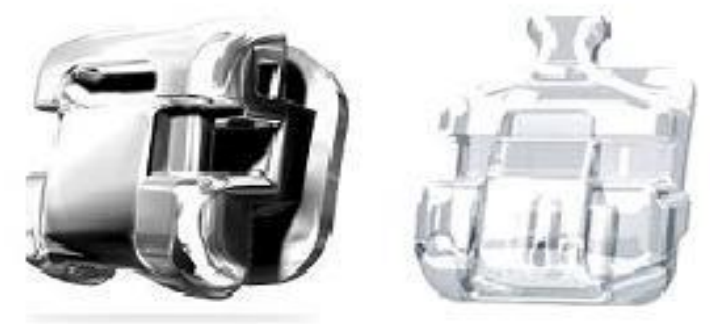

\section{Damon Aesthetic (2009)}

The new Damon Clear bracket is a translucent passive self-ligation bracket with no metal insert. The bracket's totally clear design is Planned to meet patients desires for aesthetics, while its strong development addresses clinicians' issues for functionality and quality. The completely stylish bracket body and slide are made of strong polycrystalline alumina (PCA), an inert material impervious to staining or discoloration. The slide of the SL bracket constitutes a fourth wall, which makes a passive lumen to hold the arch wire set up with low ligation force while encouraging rotational control. A nickel-titanium (Ni-Ti) spring component keeps up the slide in the open and close positions and shields the slide from isolating from the bracket body.
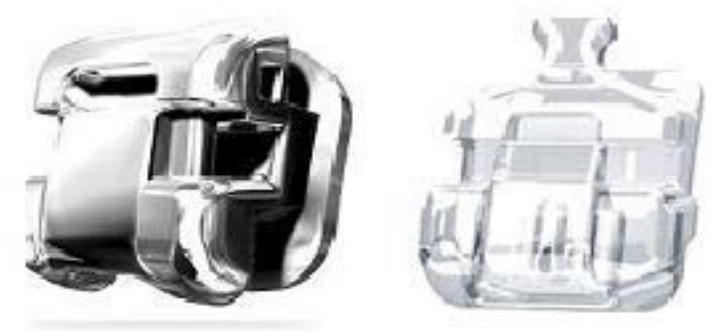

\section{Smart clip SL3 (2009)}

It is like Smartclip bracket, distinction is less clip force reduction. Additionally accessible in adhesive precoated framework with fluoride discharge property. Familiar Twin-Wing configuration takes into consideration treatment adaptability and specific bracket or tie-wing ligation, expanding between bracket width when Needed.

- Arch wire addition is finished with finger pressure and disengagement finished with separation device has two hooks to engage the wire, and its central part holds over the buccal surface of the mesial and distal wings.

- By methods for pressing the handles together, the wire withdraws from the bracket slot.
- Tandem Archwires Significant outcomes have been seen in adjusting rotations and making leveling and alignment when utilizing Tandem arch wires with $3 \mathrm{M}$ Self Ligating Appliances
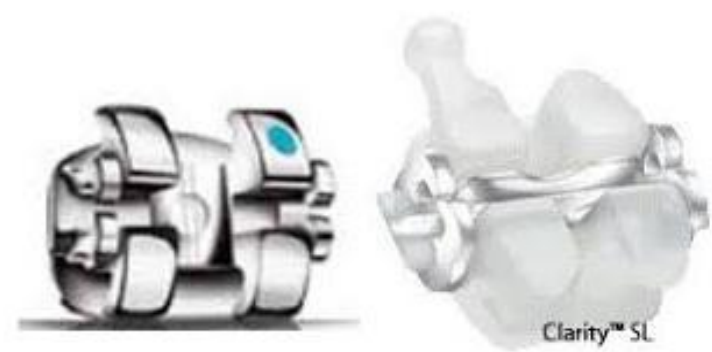

\section{Cabriolet Self-Ligating Bracket}

The Cabriolet passive-active self-ligating bracket includes a ceramic body and stain steel hinge for quality, a metal slot inserts for lessened friction, and a polymer snap-on door for simple opening and shutting and enhanced patient comfort. Each bracket incorporates a centered T-hook for elastics. The bases are intended for simplicity of debonding [35].

\section{Harmony lingual self-ligating bracket system17 (2011)}

The harmony lingual self-ligating bracket framework creates completely modified bonding pads and mechanically shaped archwires that move teeth productively and precisely, as indicated by the company. The bracket body is intended to ensure its self-ligating clip, which offers passive, interactive, or active ligation, depending upon wire size.

\section{Sensation Active Ceramic Self-Ligating Bracket:}

The Sensation Active Ceramic Self-Ligating Bracket is created from a durable and translucent ceramic material and highlights a rhodium-covered treated steel clip. A one of a kind guide rail settles opening and shutting forces of the bracket clip, bringing about quicker archwire changes.

\section{BioQuick Self-Ligating Bracket}

Forestadent's BioQuick self-ligating bracket presently includes a lower profile and rounder edges for enhanced patient comfort. The upgraded clip's thickness has been expanded by $20 \%$, making it more strong and ready to withstand disfigurement while giving better control of angulation, rotation, and torque 


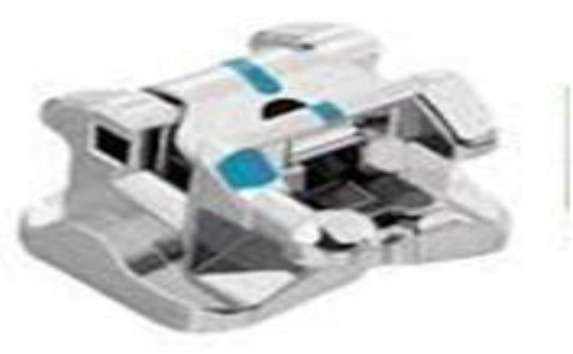

\section{Carriere SLX Self-Ligating Bracket System}

The new Carriere SLX Self-Ligating Bracket system from Henry Schein Orthodontics offers an advanced variant of the Damon solution with enhancements in bracket arrangement, torque control, and accuracy finishing. The bracket includes an amazingly low profile and occlusally opening doors; visual signs including six horizontal and five vertical references are intended to help guarantee exact bracket arrangement [36].

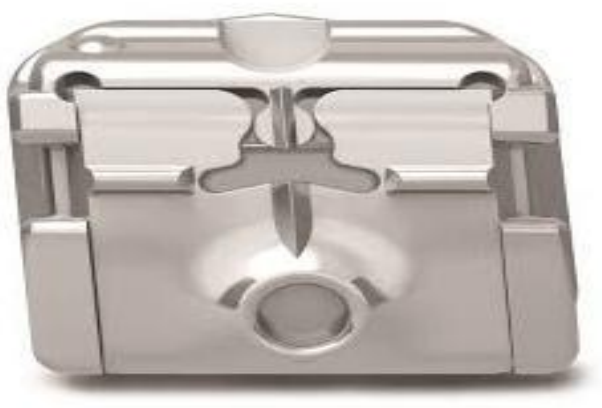

\section{Empower 2}

An overhauled variant of Empower selfligating bracket system, now known as Empower 2. New highlights incorporate micro-etched bonding pads, intended to enhance bond strength by $15-30 \%$ over different bases, and a thicker clip to expand wireseating power while staying away from clip disfigurement [37].

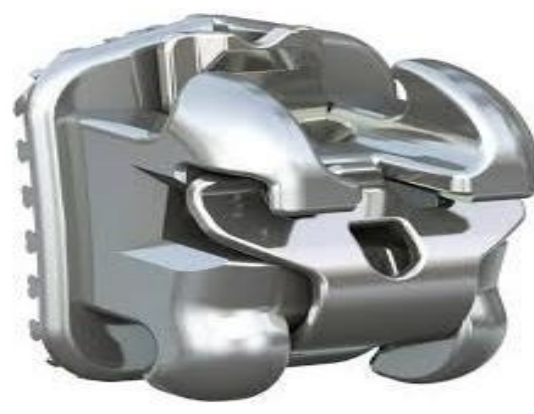

\section{In-Ovation $X$}

In-Ovation X, Dentsply Sirona's most recent expansion to its self-ligating In-Ovation line, holds a similar core design and treatment standards, with improvements including a streamlined shape and a diminished profile and occlusal impression. There is an updated encased-clip system and shut gingival bracket base will decrease the calculus develop that can hinder with clip function [38].

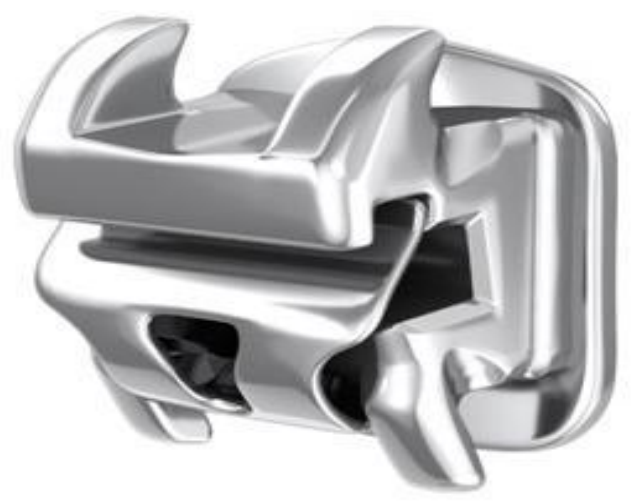

\section{CONCLUSION}

Self-ligating bracket systems were built on the philosophy of delivering light forces on a lowfriction basis, thus insuring more physiologic tooth movement and at balanced oral interplay. These systems have been gaining popularity in recent years with a host of claimed advantages over conventional appliance systems relating to reduced overall treatment time, less associated subjective discomfort, promotion of periodontal health, superior torque expression, and more favourable arch dimensional change. Other claimed advantages include possible anchorage conservation, greater amounts of expansion, less proclination of anterior teeth, less need for extractions, and better infection control.

\section{REFERENCES}

1. Cacciafesta V, Sfondrini MF, Ricciardi A, Scribante A, Klersy C, Auricchio F. Evaluation of friction of stainless steel and esthetic self ligating brackets in various bracket-archwire combinations. Am J Orthod Dentofacial Orthop. 2003; 124:395-402.

2. Damon DH. The rationale, evolution and clinical application of the self-ligating bracket. Clin Orthod Res. 1998; 1:52-61.

3. Kim TK, Kim KD, Baek SH. Comparison of frictional forces during the initial leveling stage in various combinations of self-ligating brackets and archwires with a custom-designed typodont system. Am J Orthod Dentofacial Orthop. 2008; 133:187.e15-24.

4. Budd S, Daskalogiannakis J, Tompson BD. A study of the frictional characteristics of four commercially available selfligating bracket systems. Eur J Orthod. 2008; 30:645-53.

5. Berger JL. The influence of the SPEED bracket's self-ligating design on force levels in tooth 
movement: a comparative in vitro study. Am J Orthod Dentofacial Orthop. 1990; 97:219-28.

6. Harradine NW. Self-ligating brackets: where are we now? J Orthod. 2003; 30:262-73.

7. Eberting JJ, Straja SR, Tuncay OC. Treatment time, outcome, and patient satisfaction comparisons of Damon and conventional brackets. Clin Orthod Res. 2001; 4:228-34.

8. Harradine NW. Self-ligating brackets and treatment efficiency. Clin Orthod Res. 2001;4:220-7.

9. Berger J, Byloff FK. The clinical efficiency of self-ligated brackets. J Clin Orthod. 2001;35:3048.

10. Maijer R, Smith DC. Time savings with selfligating brackets. J Clin Orthod 1990;24:29-31.

11. Shivapuja PK, Berger J. A comparative study of conventional ligation and self-ligation bracket systems. Am J Orthod Dentofacial Orthop. 1994; 106:472-80.

12. Paduano S, Cioffi I, Iodice G, Rapuano A, Silva R. Time efficiency of self-ligating vs conventional brackets in orthodontics: effect of appliances and ligating systems. Prog Orthod. 2008; 9:74-80.

13. Forsberg CM, Brattstrom V, Malmberg E, Nord CE. Ligature wires and elastomeric rings: two methods of ligation, and their association with microbial colonization of Streptococcus mutans and lactobacilli. Eur J Orthod. 1991; 13:416-20.

14. Read-Ward GE. A Comparison of Self-ligating and Conventional Orthodontic Bracket Systems. British Journal of Orthodontics. 1997; 24:309317.

15. Orthodontics current principles and techniques .Graber Vanarsdall. Sixth edition. 731.

16. Nigel Harradine. The history and development of self-ligating brackets. Semin orthod. 2008; 14:518.

17. Nigel Harradine. The history and development of self-ligating brackets. Semin orthod. 2008; 14:5.

18. Harradine NWT. Self-ligating brackets: where are we now? J Orthod. 2003; 30: 262-73.

19. Harradine NWT. Self-ligating brackets: where are we now? J Orthod. 2003; 30: 262-73.

20. Orthodontics current principles and techniques .Graber Vanarsdall. Sixth edition. 731.
21. Stolzenberg J. The Russell attachment and its improved advantages. Int J Orthod Dent Child. $1935 ; 21: 837-840$.

22. Theodore eliades, nikolas pandis, self ligation in orthodontics. $1^{\text {st }}$ edition.

23. Nigel TH, David JB. The clinical use of Activa self-ligating bracket. Am J Orthod Dentofacial Orthop. 1996; 109:319-28.

24. Wolfgang H. A new orthodontic philosophy. J Clin Orthod. 1998; 35:44-53.

25. Orthodontics current principles and techniques. Graber Vanarsdall. Sixth edition: 733.

26. Gottlieb EL, Wildman AJ, Hice TL, Lang HM, Lee IF, Strauch Jr EC. The Edgelok bracket. Journal of clinical orthodontics: JCO. 1972 Nov;6(11):613.

27. Orthodontics current principles and techniques .Graber Vanarsdall. Sixth edition, 733.

28. Theodore eliades, nikolas pandis self ligation in orthodontics. $1^{\text {st }}$ edition.

29. Geron S. Self-Ligating Brackets in Lingual Orthodontics, Seminars in Orthodontics, 2008 March; 14(1):64-72.

30. Geron S. Self-Ligating Brackets in Lingual Orthodontics, Seminars in Orthodontics, 2008 March; 14(1):64-72.

31. Trevisi and Bergstrand: The Smart Clip SelfLigating Appliance System; Semin Orthod. 2008; 14:87-100.

32. Orthodontics current principles and techniques .Graber Vanarsdall.

33. Harradine N. The history and development of selfligating brackets. In Seminars in orthodontics 2008 Mar 1 (Vol. 14, No. 1, pp. 5-18). WB Saunders.

34. Vision Why Self Ligation? www.americanortho.com

35. Cabrio Cabriolet the clear hybrid, self-ligating ortho appliance, www.gestenco.com.

36. Carrier slx What are self-ligating braces? Carriere SLX Self- Ligating Braces, www.HenryScheinOrtho.com.

37. Empower 2 American Orthodontics' Empower® 2 Self Ligating metal brackets, march 2017, www.americanortho.com

38. Innov In-Ovation X Self-Ligating Metal Bracket Design Features and Advantages, dentsplysirona.com 